\title{
Wind turbine inverter robust loop-shaping control subject to grid interaction effects
}

Gryning, Mikkel Peter Sidoroff; Wu, Qiuwei; Blanke, Mogens; Niemann, Hans Henrik; Andersen, Karsten P.H.

Published in:

IEEE Transactions on Sustainable Energy

Link to article, DOI:

10.1109/TSTE.2015.2472285

Publication date:

2015

Document Version

Peer reviewed version

Link back to DTU Orbit

Citation (APA):

Gryning, M. P. S., Wu, Q., Blanke, M., Niemann, H. H., \& Andersen, K. P. H. (2015). Wind turbine inverter robust loop-shaping control subject to grid interaction effects. IEEE Transactions on Sustainable Energy, 7(1), 41-50. https://doi.org/10.1109/TSTE.2015.2472285

\section{General rights}

Copyright and moral rights for the publications made accessible in the public portal are retained by the authors and/or other copyright owners and it is a condition of accessing publications that users recognise and abide by the legal requirements associated with these rights.

- Users may download and print one copy of any publication from the public portal for the purpose of private study or research.

- You may not further distribute the material or use it for any profit-making activity or commercial gain

- You may freely distribute the URL identifying the publication in the public portal 


\title{
Wind turbine inverter robust loop-shaping control subject to grid interaction effects
}

\author{
Mikkel P.S. Gryning, SM, IEEE, Qiuwei Wu, Member, IEEE, Mogens Blanke, Senior Member, IEEE, \\ Hans Henrik Niemann and Karsten P.H. Andersen
}

\begin{abstract}
An $\mathcal{H}_{\infty}$ robust control of wind turbine inverters employing an LCL filter is proposed in this paper. The controller dynamics are designed for selective harmonic filtering in an offshore transmission network subject to parameter perturbations. Parameter uncertainty in the network originates from the grid and the number of wind turbines connected. Power converter based turbines inject harmonic currents, which are attenuated by passive filters. A robust high order active filter controller is proposed to complement the passive filtering. The $\mathcal{H}_{\infty}$ design of the control loop enables desired tracking with integral effect while bounding the induced change. The design was tested in an aggregated model of the London Array offshore wind power plant and compared with traditional PI controller designs. Robust stability and performance and a reduction of control effort by $25 \%$ are obtained over the full envelope of operation.
\end{abstract}

Index Terms-Inverters, Power conversion harmonics, Power system control, Robust Control, Wind farms.

\section{INTRODUCTION}

$\mathbf{O}$ FFSHORE wind turbines (WT) are increasing in power rating. Turbine output control requirements have been extended as the power rating has increased. The requirements have been further extended by the move to a power electronic interface. Modern type- 4 wind turbines are interfaced to the point of common coupling (PCC) by current-controlled voltage source inverter (VSI) systems [1], [2]. VSIs have fast dynamic response and high quality of the power injection [3]. The current contains components at switching frequency caused by the pulse-width modulation (PWM) switching process [4], [5]. Additionally, the controlled output current is disturbed by polluted PCC voltage due to harmonics of the fundamental power frequency and harmonic resonance in the offshore transmission network [6].

Damping of switching frequency components by L, LC or LCL ac-side filter improves attenuation [7]. L filters require high frequency switching and in high power applications, such as wind turbines, the switching frequency is kept low to reduce losses [8]. The LCL filter provides ideally $60 \mathrm{~dB}$ per decade harmonic rejection compared with $20 \mathrm{~dB}$ of the $\mathrm{L}$ filter at lower inductance values hence makes lower switching frequencies possible [8]. The LCL filter attenuates the harmonics within the first carrier group, and additional damping of $2^{\text {nd }}$ and $3^{\text {rd }}$ order harmonics is achieved using trap filters [9].

M. Gryning is with DONG Energy and Department of Electrical Engineering, Technical University of Denmark, e-mail: migry@ dongenergy.dk

K. Andersen is with DONG Energy, 2820 Gentofte, Denmark, e-mail: kahan@ dongenergy.dk

Q. Wu, M. Blanke and H.H. Niemann are with Department of Electrical Engineering, Technical University of Denmark, 2800 Kgs. Lyngby, Denmark, e-mail: qw@elektro.dtu.dk, mb@elektro.dtu.dk and hhn@elektro.dtu.dk
A challenge in the LCL filter design is the resonance characteristic [10]. Active converter resonance damping was proposed for an LC filter by injecting a damping voltage proportional to the filter capacitance [11]. This virtual resistor control loop was extended to LCL filters to damp resonance peaks [12]. An optimal virtual resistor value was found to be a function of the LCL filter resonance frequency and capacitance [13]. However, impedance seen from the inverter is only partially known at the design state, leading to suboptimal resistor values and decreased damping under uncertain conditions [14]. The sideband harmonics in a resonant grid contains multiples of the power system fundamental and will excite undamped system dynamics [15]. Transmission system uncertainty extends the envelope of parameters, and control must encapsulate both uncertainty and power system harmonics [16].

This can be achieved by using grid voltage feed forward to suppress induced current distortion with proportionalresonant(PR) control. PR control introduces an infinite gain at a selected resonant frequency [17]. Repetitive control (RC) extends the idea to a a parallel combination of PI and many resonant controllers [18]. Hybrid designs such as a combination of PR with odd harmonic RC were proposed by [19]. The RC theory was extended to an adaptive solution by [20], and robust RC control wrt. grid frequency change was introduced by [21]. Multiple PI controllers in the $d q 0$ were introduced as a variation of PR in the $\alpha \beta \gamma$ reference frame in [18]. Hysteresis Band and nonlinear sliding mode control strategies were suggested in [22] and [23].

This paper takes another route by suggesting a control design that combines robust performance and selective filtering. A single repetitive $\mathcal{H}_{\infty}$ design is introduced by cascading notch filters in the synthesis. This enables a wide bandwidth of the notch filters without sacrificing performance while guaranteeing stability in the full envelope of operation. A major contribution is the novel idea of ensuring low attenuation of system frequency harmonics to minimize cascade-controller interaction. The network is aggregated and the WTs are a controllable voltage source with harmonic distortion. This enables a study of the interaction between the network, grid and VSI dynamics for varying parameters.

The paper is organized as follows. After a discussion on control requirements, an analytical model is introduced and uncertainty is discussed. Evaluation criteria are then defined and an $\mathcal{H}_{\infty}$ controller is designed and compared with the traditional controllers in simulation, followed by conclusions. 


\section{Control ReQuirements}

Using an LCL filter requires damping of the grid-converter resonance with robustness against perturbations of system parameters. The resonance frequency of an LCL filter with known grid inductance $L_{g}$ is

$$
\omega_{r e s}=\sqrt{\frac{L_{f 1}+L_{f 2}+L_{g}}{L_{f 1}\left(L_{f 2}+L_{g}\right) C_{f}}},
$$

which determines the amount of damping needed in the control system [24]. If $L_{g}$ is uncertain, there exists a large envelope of operation which opts for a robust control design. The system harmonics of other WTs acts as a disturbance on the inverter control through the voltage at the PCC. The attenuation of a voltage disturbance at the grid to a net change in injected current from the inverter is harmonic admittance [25].

Fig. 1 shows the harmonic admittance of the system with two distinct resonance frequencies. The resonant frequency of the LCL filter given by equation 1 is located at $965 \mathrm{~Hz}$ and its effect must be damped by the control system. The

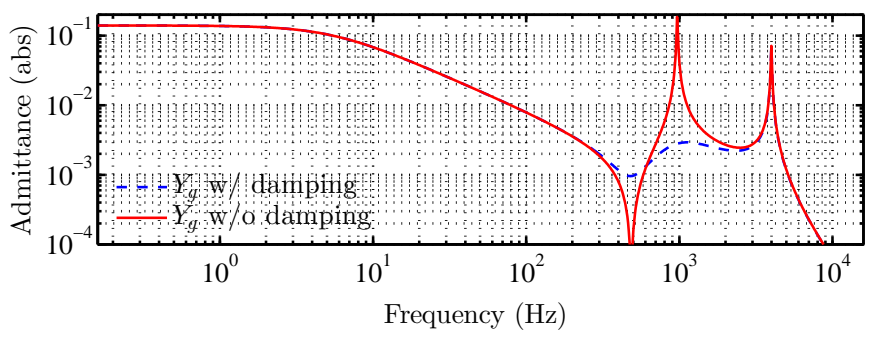

Fig. 1. Open loop sensitivity function of equation 5. Harmonic admittance w/ damping, $i_{f 2} / v_{g}$, is adequate. Control design must minimize control effort while not attenuating the power system spectra.

topology of the VSI and the voltage modulator switching frequency $f_{s}$ sets the maximum obtainable bandwidth of the control system. A compromise between disturbance rejection and reference tracking is $f_{b i}=f_{s} / 5$ [26]. For $5 M W$ class converters, switching losses dictate a low frequency of $1-2 k H z$ [27]. The crossover frequency for control then needs to be located around $f_{b i}=2 k H z / 5=0.4 k H z$ to ensure proper attenuation of switching harmonics.

The control structure and decoupling feedback is shown in Fig. 2. The current injection due to potential changes in the grid and collector system is shown as output disturbances. The reference current is an externally generated signal, normally from a DC-link controller.

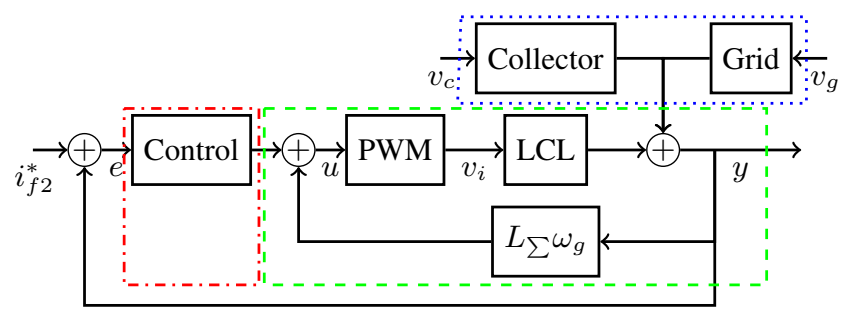

Fig. 2. Certain system model of closed loop control. Control(dashdot), plant(stipple) and disturbances(dotted).
The ideal control requirements for the system are:

- Low attenuation of odd harmonics of the fundamental power system frequency as they are the most prominent harmonics in the current spectrum [28], i.e. sensitivity function gain of $1-\epsilon, \epsilon \in[0.1 ; 0.2] \forall \omega \in \omega_{h}$.

- Tracking of $a b c 50 \mathrm{~Hz}$ fundamental, steady state in $d q$ with bandwidth $f_{b i}=0.4 k H z$.

- Maximum overshoot of $20 \%$.

- Roll-off of output disturbance to control signal of $40 \mathrm{~dB}$ at $f_{b i}$.

The Measurement noise of the transformer inductor currents is attenuated by the notch filter characteristic for the selected power system harmonics. Outside of the controller bandwidth, the LCL filter ensures an attenuation of $60 \mathrm{~dB} / \mathrm{dec}$. These requirements must be met for uncertainties in the range specified in TABLE I.

\section{Three-Phase CuRRENT-CONTROLLED VSI With LCL FILTER}

The system topology of a VSI with a LCL filter is shown in Fig. 3, where $L_{f 1}$ and $L_{f 2}$ are the filter inductance. $R_{f 1}$ represents the inverter switching losses, $R_{f 2}$ is the copper losses of inductor $L_{f 2}$, and $C_{f}$ is the filter capacitance. The inductor $L_{g}$ and resistance $R_{g}$ are the grid side inductance and resistance seen from the terminals of the transformer. The collector network is modelled by a lumped capacitance $C_{c}$, a resistance $R_{c}$ and an inductance $L_{c}$. The grid voltage is $v_{g}$; the capacitor voltage is $v_{c f} ; i_{f 1}, i_{f 2}$ and $i_{g}$ represents the inverter output currents and the injected transformer current respectively, and the voltage at the inverter output terminals is $v_{i}$. The total inductance seen from the terminals of the capacitors is given by $L_{t}=L_{f 2}+L_{g}$ and the resistance $R_{t}=R_{f 2}+R_{g}$. The collector network is modeled as a controlled voltage source and an equivalent impedance using the NREL aggregation method, taking into account each element upstream of the VSI [29], [30]. The collector system is based on the London Array project and uses string 12 on substation 2 as a standard reference for connecting $m$ identical strings to the busbar. Each string consists of $n_{1}$ wind turbines $650 \mathrm{~m}$ apart connected by underground cable. The cables are of type $500 \mathrm{~mm}^{2}\left(t_{2}\right)$ for the first $n_{2}$ WTs in the string and type $150 \mathrm{~mm}^{2}\left(t_{1}\right)$ for the remaining. The aggregated impedance of one string equals,

$$
\boldsymbol{Z}_{\boldsymbol{s}}=\frac{\sum_{k=1}^{n_{1}-n_{2}} k^{2} Z_{k}^{t_{1}}}{\left(n_{1}-n_{2}\right)^{2}}+\frac{\sum_{k=\left(n_{1}-n_{2}+1\right)}^{n_{1}} k^{2} Z_{k}^{t_{2}}}{n_{2}^{2}}
$$

and the parallel connection of the aggregated strings to the busbar is,

$$
\boldsymbol{Z}_{\boldsymbol{c}}=\frac{\sum_{k=1}^{m}\left(n_{k}^{2} Z_{s}^{k}\right)}{\left(\sum_{k=1}^{m} n_{k}\right)^{2}}=\frac{m n_{1}^{2} \boldsymbol{Z}_{s}}{\left(m n_{1}\right)^{2}},
$$

as the strings are assumed identical. The capacitance in the cables are represented in the system as,

$$
\boldsymbol{C}_{\boldsymbol{c}}=\sum_{k=1}^{m}\left(\sum_{h=1}^{n_{1}-n_{2}} C_{h}^{t_{1}}+\sum_{h=n_{1}-n_{2}+1}^{n_{1}} C_{h}^{t_{2}}\right) .
$$




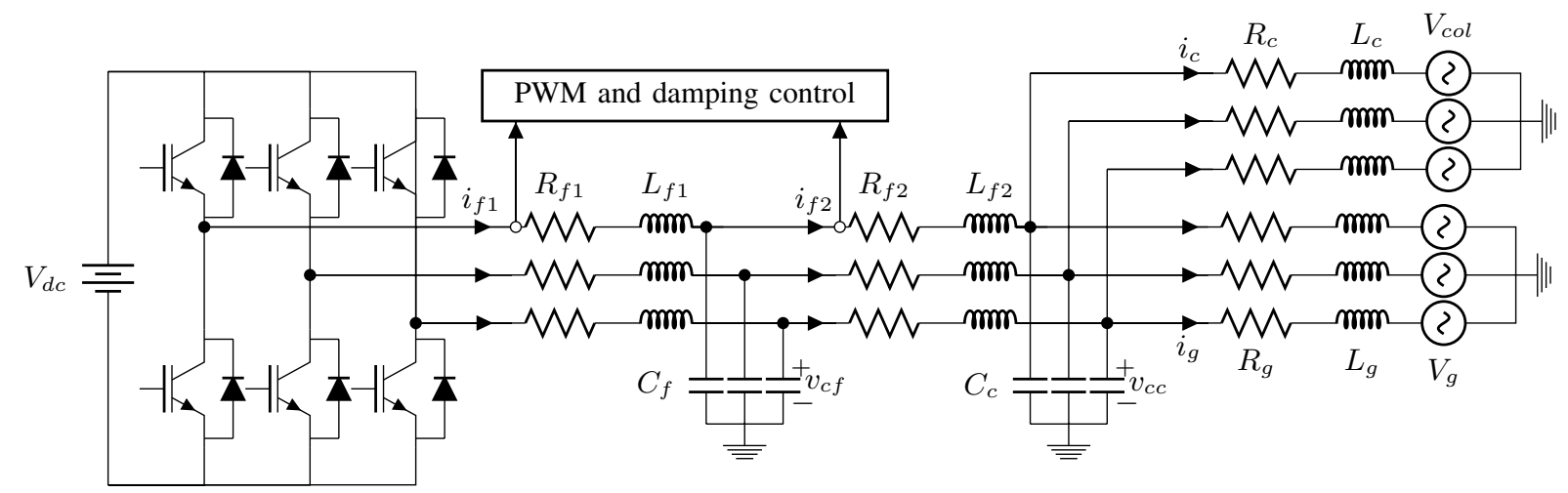

Fig. 3. Three-phase VSI with LCL filter connected to grid and transmission network.

TABLE I

RELATIVE UNCERTAINTY IN SYSTEM PARAMETERS

\begin{tabular}{|l|l|c|c|}
\hline Potential & Structure & Element & Uncertainty \pm \\
\hline $0.69 k V \mathrm{LV}$ & LCL Filter & $C_{f}, Z_{f 1}$ & $15 \%$ \\
& & $Z_{f 1}, Z_{f 2}$ & \\
\hline $33 k V \mathrm{HV}$ & Collector & $C_{c}, L_{c}, R_{c}$ & $75 \%$ \\
& Grid & $L_{g}, R_{g}$ & \\
\hline
\end{tabular}

The aggregated system is uncertain in its parameters. The uncertainties in the collector cables, grid and internal filter are listed in TABLE I. Space vector transformation and measurement of the line voltage enables the transformation of the system equations into Park's d-q frame rotating synchronously with the grid angular speed. Assuming that the mutual capacitance and inductance between the phases are zero, the dynamics of the inverter is transformed to,

$$
\begin{gathered}
L_{f 1} \frac{d i_{f 1}^{d q}}{d t}+R_{f 1} i_{f 1}^{d q}=v_{i n v}^{d q}-v_{c f}^{d q}-v_{d}^{d q}+D L_{f 1} D \omega i_{f 1}^{d q} \\
L_{f 2} \frac{d i_{f 2}^{d q}}{d t}+R_{f 2} i_{f 2}^{d q}=a v_{c c}^{d q}-v_{c f}^{d q}-v_{d}^{d q}+D L_{f 2} D \omega i_{f 2}^{d q} \\
L_{c} \frac{d i_{c}^{d q}}{d t}+R_{c} i_{c}^{d q}=a^{2} v_{c c}^{d q}-a^{2} v_{c o l}^{d q}+D L_{c} D \omega i_{c}^{d q} \\
L_{g} \frac{d i_{g}^{d q}}{d t}+R_{g} i_{g}^{d q}=a^{2} v_{g}^{d q}-a^{2} v_{c c}^{d q}+D L_{t} D \omega i_{g}^{d q} \\
C_{f} \frac{\boldsymbol{d} v_{c f}^{d q}}{d t}=i_{f 1}^{d q}+i_{f 2}^{d q}+D C_{f} D \omega v_{c}^{d q} \\
C_{c} \frac{\boldsymbol{d} v_{c c}^{d q}}{d t}=\left(1 / a^{2}\right)\left(i_{g}^{d q}-i_{c}^{d q}\right)-(1 / a) i_{f 2}^{d q}+D C_{c} D \omega v_{c}^{d q}
\end{gathered}
$$

where,

$$
\boldsymbol{\omega}=\left[\begin{array}{cc}
0 & \omega_{g} \\
-\omega_{g} & 0
\end{array}\right] \quad \boldsymbol{D}=\left[\begin{array}{ll}
0 & 1 \\
1 & 0
\end{array}\right],
$$

and $\boldsymbol{L}_{\boldsymbol{f 1}}, \boldsymbol{L}_{\boldsymbol{f} \mathbf{2}}, \boldsymbol{L}_{\boldsymbol{c}}, \boldsymbol{L}_{\boldsymbol{g}}, \boldsymbol{R}_{f 1}, \boldsymbol{R}_{\boldsymbol{f} \mathbf{2}}, \boldsymbol{R}_{\boldsymbol{c}}, \boldsymbol{R}_{\boldsymbol{g}}, \boldsymbol{C}_{\boldsymbol{f}}$ and $\boldsymbol{C}_{\boldsymbol{c}}$ are diagonal matrices with the dimensions $2 \times 2 \in \Re^{+}$composed of the nominal values of the components in the dq frame projected to the primary side of the transformer, $a$ is the padmounted transformer ratio given by $0.69 k \mathrm{k} / 33 \mathrm{kV}$ and $\boldsymbol{v}_{\boldsymbol{d}}^{\boldsymbol{d q}}$ is the potential difference across a virtual damping resistor. The nominal system component values are frequency dependent. This frequency dependence is comprised in the system uncertainty description. The system frequency $\omega_{g}$ is assumed to be constant. The model is bounded by the limits of the physical system given by the switching technology used in the VSI. The injected current is limited by the maximum current rating of the inverter, and the load voltage at the terminals is limited to the maximum output voltage of the inverter. The LCL filter added to the system to attenuate the switching harmonics has an unwanted resonance frequency that should be damped to enable the design of a high-bandwidth current controller and mitigate the grid-inducted distortion. The LCL filter resonance can be damped by injecting a damping voltage proportional to the capacitor current in the filter [12]. The injected damping voltage is introduced by defining the damping resistance $R_{d}$ and the decoupling voltage,

$$
v_{d}^{d q}=R_{d}\left(i_{f 1}^{d q}+i_{f 2}^{d q}\right) .
$$

It should be noted that the use of a directly measured capacitor current could inject noise into the system, and one could use a low-pass filtered signal to overcome this issue. Assuming that the system in (5) is decoupled by feedback and no collector system present, the damping properties of the system wrt. the choice of damping resistor $R_{d}$ can be investigated. The nominal value of the resistor is [25],

$$
R_{d}=\frac{1}{3 \omega_{\text {res }} C_{f}} .
$$

Given that the virtual resistance is calculated from the nominal resonant frequency of the LCL filter, the damping properties of the chosen resistance will change with parametric uncertainty of the grid inductance. Addtive uncertainty on $L_{g}$ is introduced as,

$$
L_{g}=L_{g n}(1+\delta) .
$$

The change of the resonant frequency of the LCL filter as a function of the uncertainty parameter $\delta$ and the nominal frequency is found to be,

$\omega_{r e s}(\delta)^{2}=\left.\frac{\left(L_{g n}+L_{f 2}\right)\left(L_{g n}(1+\delta)+L_{f 1}+L_{f 2}\right)}{\left(L_{g n}(1+\delta)+L_{f 2}\right)\left(L_{f 1}+L_{f 2}+L_{g n}\right)} \omega_{r e s}^{2}\right|_{\delta=0}$.

The virtual resistance was determined from the nominal resonant frequency and its attenuation properties from inverter voltage to grid current $H(s)$, will change as

$$
\left|\frac{\left.H\left(\omega_{r e s}\right)\right|_{\delta=\delta}}{\left.H\left(\omega_{r e s}\right)\right|_{\delta=0}}\right|=\frac{L_{g n}+L_{t}}{L_{g n}(1+\delta)+L_{f 1}+L_{f 2}} .
$$


Equation (11) shows that the attenuation of the resonant peak at the perturbed resonant frequency will decrease with increased $\delta$. The magnitude of the change is a function of the relation between the inverter side inductance and the grid side inductance. Minimization of costs opts for lower values of $L_{f 1}$ which then increases the effect of a change in the uncertain parameter $L_{g}$, which determines the control requirements needed for operation in an uncertain grid.

\section{A. Uncertain Continuous Time State-Space Model}

External voltage disturbances and uncertainty in the system parameters wrt. both cross coupling and active damping requires an uncertain formulation of the system dynamics. The uncertainty of parameters should be included in the system model in addition to possible unmodelled internal dynamics and time delays. The system can be formulated as a nominal system with dynamic disturbances and perturbations of the parameters.

$$
\begin{aligned}
\frac{d \boldsymbol{x}(t)}{d t} & =\boldsymbol{A}_{\mathbf{0}} \boldsymbol{x}(t)+\boldsymbol{B}_{\mathbf{0}} \boldsymbol{u}(t)+\boldsymbol{E}_{\mathbf{0}} \boldsymbol{d}(t)+\boldsymbol{W}_{\mathbf{0}} \boldsymbol{x}(t) \\
y(t) & =\boldsymbol{C} \boldsymbol{x}(t),
\end{aligned}
$$

where

$$
\begin{aligned}
& x(t)=\left[\begin{array}{llllll}
i_{f 1}^{d q} & i_{f 2}^{d q} & i_{c}^{d q} & i_{g}^{d q} & v_{c f}^{d q} & i_{c c}^{d q}
\end{array}\right]^{\top} \\
& u(t)=\left[v_{i n v}^{d q}\right]^{\top}, d(t)=\left[\begin{array}{ll}
v_{c o l}^{d q} & v_{g}^{d q}
\end{array}\right],
\end{aligned}
$$

with $\boldsymbol{C}=\boldsymbol{I}$ and $\boldsymbol{A}_{\mathbf{0}}, \boldsymbol{B}_{\mathbf{0}}, \boldsymbol{E}_{\mathbf{0}}$ and $\boldsymbol{W}_{\mathbf{0}}$ as shown in (14). The uncertainty is represented by the uncertain time delay of the actuator and parametric uncertainty on each of the electrical elements of the system listed in TABLE I. The general parameter $\alpha$ is with added uncertainty given as $\alpha=\alpha_{0}+\delta_{\alpha}$, which results in the uncertain state-space representation,

$$
\begin{aligned}
\frac{d \boldsymbol{x}(t)}{d t} & =\left(\boldsymbol{A}_{\mathbf{0}}+\boldsymbol{A}_{\boldsymbol{u}}\right) \boldsymbol{x}(t)+\left(\boldsymbol{B}_{\mathbf{0}}+\boldsymbol{B}_{\boldsymbol{u}}\right) \boldsymbol{u}_{\boldsymbol{u}}(t) \\
& +\left(\boldsymbol{E}_{\mathbf{0}}+\boldsymbol{E}_{\boldsymbol{u}}\right) \boldsymbol{d}(t)+\boldsymbol{W}_{\mathbf{0}} \boldsymbol{x}(\boldsymbol{t}) \\
\boldsymbol{u}_{\boldsymbol{u}}(t) & =\boldsymbol{F}(s) \boldsymbol{u}(t), y(t)=\boldsymbol{C} \boldsymbol{x}(t),
\end{aligned}
$$

where the subscript 0 denotes the nominal system parameters, and $u$ is the uncertain perturbations. $\boldsymbol{F}(s)$ is the actuator transfer function matrix and is included as an uncertain time delay. The set of possible plants is illustrated in Fig. 4. The linear system with uncertainty in (15) can be rewritten as two identical decoupled SISO systems with multiplicative uncertainty in the Laplace domain by introducing frequency dependent uncertainty regions. Component uncertainty with respect to values and frequency dependency is contained in the uncertainty regions. The output of such system with uncertainty weight $W_{O}(s)$ and $0 \leq \Delta \leq 1$ is given as,

$$
y(s)=\left[\begin{array}{c}
\left(1+W_{O}(s) \Delta\right) G_{i_{f 2} v_{i n v}}(s) \\
G_{i_{f 2} v_{g}}(s) \\
G_{i_{f 2} v_{c o l}}(s)
\end{array}\right]^{\top}\left[\begin{array}{c}
v_{i n v}(s) \\
v_{g}(s) \\
v_{c o l}(s)
\end{array}\right],
$$

where $\Delta=1$ would represent $100 \%$ uncertainty. Omitting the Laplace operator, the closed-loop system output is,

$$
y=\underbrace{\frac{G K}{I+G K}}_{T} r+\underbrace{\frac{1}{I+G K}}_{S} G_{d} d-\underbrace{\frac{G K}{I+G K}}_{T} n
$$

where $G=\left(1+W_{O}(s) \Delta\right) G_{i_{f 2}}$ and $K$ is the controller. System theory states that $S+T=1$, which shows that ideal fulfillment of objective one in section II would provide perfect noise rejection. The system setup is further described in section IV-D.

\section{VSI CONTROLLER DESIGN}

The PI controller is the best candidate for regulating DC values with zero steady state error due to its infinite DC gain. $\mathrm{PR}$ control and RC are not able to guarantee a closed-loop unity attenuation of power system harmonics. The PI control is therefore used as comparison to the $\mathcal{H}_{\infty}$ controller. The filter capacitor can be neglected with the approximation that the LCL-filter converges to a simple L filter at low frequencies [8]. Generalized parameter estimation techniques such as symmetrical optimum ( $\mathrm{SO}$ ) or magnitude optimum (MO) are traditionally used for control design [31]. Requirements for the control system are bandwidth and overshoot [32]. Internal mode control (IMC) is considered as a closed loop systematic approach for parameter specification [33]. A major disadvantage of the PI control design is the inability to shape the disturbance rejection loop at the harmonic frequencies. The PI control law for the VSI system is given by,

$$
\boldsymbol{u}(t)=\boldsymbol{L}_{\sum} \boldsymbol{\omega}_{\boldsymbol{g}}\left[\begin{array}{c}
i_{f 2}^{d} \\
i_{f 2}^{q}
\end{array}\right]+\boldsymbol{K}_{\boldsymbol{p}} \boldsymbol{e}_{\boldsymbol{f} \mathbf{2}}^{\boldsymbol{q}}+\boldsymbol{K}_{\boldsymbol{i}} \int \boldsymbol{e}_{\boldsymbol{f 2}}^{\boldsymbol{d q}} d t,
$$

where the error signal $e_{f 2}^{d q}=r_{f 2}^{d q}-i_{f 2}^{d q}$ and

$$
\boldsymbol{L}_{\sum}=\boldsymbol{L}_{\boldsymbol{f 1}}+\boldsymbol{L}_{\boldsymbol{f 2}}+a \boldsymbol{L}_{\boldsymbol{g}}
$$

$K_{p}$ and $K_{i}$ are found for SO, MO and IMC given equal performance criteria defined in section II.

\section{A. Magnitude optimum}

Low order plants without time delay and one dominant time constant is often tuned using the magnitude optimum criteria. For a general second order system,

$$
G(s)=\left(1+\tau_{1} s\right) /(1+\sigma s) K^{-1}
$$

where $\sigma$ is the sum of parasitic time constants smaller that $\tau_{1}$, it has the solution [34],

$$
K_{i}=\frac{1}{2 K}\left(\frac{1}{\sigma}+\frac{1}{\tau_{1}}-\frac{1}{\tau_{1}+\sigma}\right), K_{p}=\frac{1}{2 K}\left(\frac{\tau_{1}}{\sigma}+\frac{\sigma}{\tau_{1}}\right)
$$

which if $\sigma<<T_{1}$ provides full cancellation of the plant pole by the controller zero.

\section{B. Symmetrical optimum}

The symmetrical optimum method aims at shaping both disturbance rejection and reference tracking by optimizing their common characteristic equation. The loop transfer function is shaped to be in the form $\omega_{0}^{2}\left(2 s+\omega_{0}\right) / s^{2}\left(s+2 \omega_{0}\right)$. A system in the form of (20) with $\tau_{1}>>\sigma$ has the solution [35],

$$
K_{p}=\frac{\tau_{1}}{\alpha K \sigma}, \quad K_{i}=\frac{\tau_{1}}{\alpha^{3} K \sigma^{2}}
$$

with typically $2 \leq \alpha \leq 3$ [36]. The closed-loop response of the system (22) has a large overshoot and a pre-filter is usually designed to shape the reference input [37]. 


$$
\begin{aligned}
& A_{0}=\left[\begin{array}{cccccc}
-\left(R_{f 1}+R_{d}\right) L_{f 1}^{-1} & -R_{d} L_{f 1}^{-1} & O_{2 x 2} & O_{2 x 2} & -L_{f 1}^{-1} & O_{2 x 2} \\
-R_{d} L_{f 2}^{-1} & -\left(R_{f 2}+R_{d}\right) L_{f 2}^{-1} & O_{2 x 2} & O_{2 x 2} & -L_{f 2}^{-1} & a L_{f 2}^{-1} \\
O_{2 x 2} & O_{2 x 2} & -R_{c} L_{c}^{-1} O_{2 x 2} & O_{2 x 2} & a^{2} L_{c}^{-1} & \\
O_{2 x 2} & O_{2 x 2} & O_{2 x 2} & R_{g} L_{g}^{-1} & O_{2 x 2} & -a^{2} L_{g}^{-1} \\
C_{f}^{-1} & C_{f}^{-1} & O_{2 x 2} & O_{2 x 2} & O_{2 x 2} & O_{2 x 2} \\
O_{2 x 2} & -\left(a C_{c}^{-1}\right) & -\left(a^{2} C_{c}^{-1}\right) & a^{2} C_{c}^{-1} & O_{2 x 2} & O_{2 x 2}
\end{array}\right] \\
& B_{0}=\left[\begin{array}{ll}
L_{f 1}^{-1} & O_{10 x 2}
\end{array}\right]^{\top} E_{0}=\left[\begin{array}{ccc}
O_{4 x 6} & \\
O_{2 x 2} & -a^{2} L_{c}^{-1} & O_{2 x 2} \\
O_{2 x 2} & O_{2 x 2} & a^{2} L_{g}^{-1} \\
& O_{4 x 6} &
\end{array}\right]^{\top} W_{0}=\left[\begin{array}{ccc}
\omega_{g} & & \\
& \ddots & \\
& & \omega_{g}
\end{array}\right]
\end{aligned}
$$

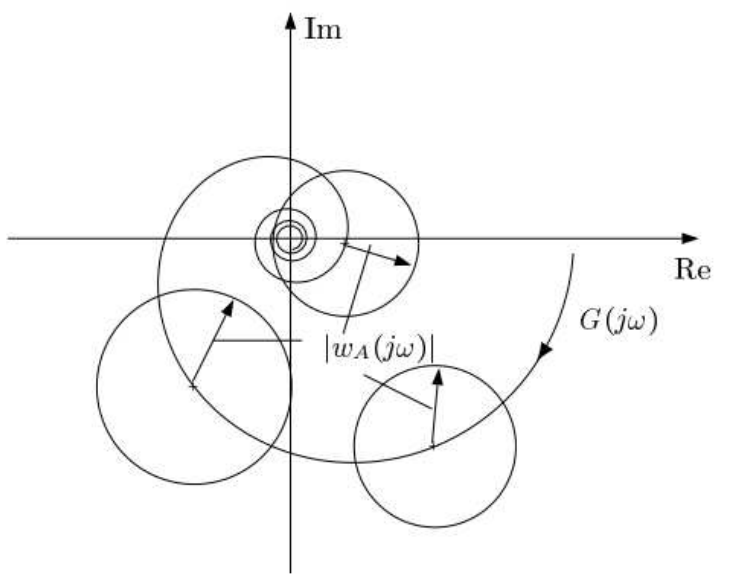

Fig. 4. Disc-shaped uncertainty regions of $G(j \omega)$ generated by complex uncertainty. The set of plants $G_{\Pi}$ at each frequency is governed by the magnitude of the weighting function $w_{A}(j \omega)$ determined by Monte-Carlo simulation with varying parameters. [38]

\section{Internal Mode Control}

IMC encapsulates that control can be achieved if the control system contains some representation of the process to be controlled. For the PI-control, the system must be approximated by a first order system. Using the half-rule [38], a second order system is approximated as,

$$
G(s)=\frac{k}{\left(\tau_{1}+\sigma / 2\right) s+1} e^{-(\sigma / 2) s}
$$

and the $P I$ parameters are given by,

$$
K_{p}=\frac{1}{k} \frac{\tau_{1}+\sigma / 2}{\tau_{c}+\sigma / 2} \quad \tau_{I}=\min \left(\tau_{1}+\sigma / 2,4\left(\tau_{c}+\sigma / 2\right)\right.
$$

where $\tau_{c}$ is a tunable parameter adjusting the tradeoff between tracking performance and input usage.

\section{D. $\mathcal{H}_{\infty}$ controller design}

The system is cast as an output disturbance problem and formulated using the generalized $P$ control structure. The dynamics of the VSI system is cast into the generalized plant representation shown in Fig. 5a where $v$ is the measured signal, $u$ is the controlled input, $w_{e}$ and $w_{i}$ are the exogenous and internal inputs and $z$ is the error signals to minimize. The set of models $G_{\Pi}$ is characterized by a matrix $\Delta$ which can

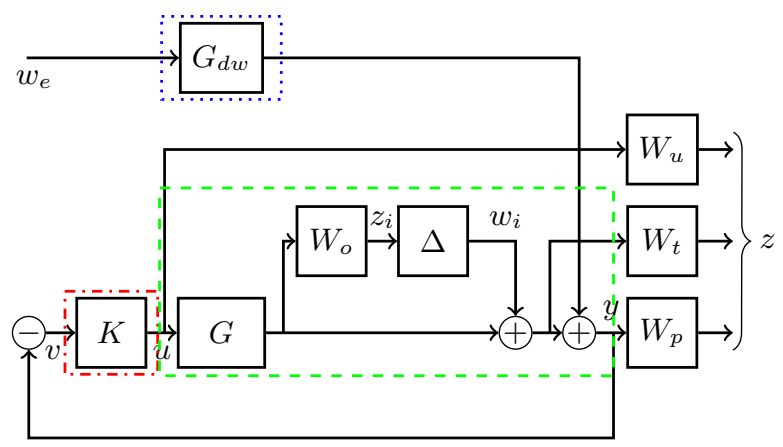

Fig. 5. a) Classic nominal control diagram of closed loop VSI control and its translation into the standard control configuration marking transformed equal areas as: Control(dashdot), plant(stipple) and disturbances(dotted). b) Standard control configuration for $\mathcal{H}_{\infty}$ synthesis with multiplicative output uncertainty $W_{o} \Delta$. Minimization of error signals $z$ shaped by weighting functions $W_{u}, W_{t}$ and $W_{p}$ including the exogenous inputs. Note that the reference signal $i_{f 2}^{*}$ is part of $G_{d w}$.

either be a full matrix or a block matrix including all possible perturbations representing uncertainty in the system, given in TABLE I. The uncertainty is represented in the frequency domain using unstructured multiplicative output uncertainty representing the set of plants $G_{\Pi}$ in an uncertainty region. The frequency domain representation is conservative as the set includes additional plants which are not specified by the direct uncertainty in the parameters. Considering the goal is to provide robust non-interacting controllers, a conservative approach is deemed as suitable. Given the nominal plant $G_{0}$, the set of plants are given by,

$$
G_{\Pi}=\left(I+L_{O}\right) G_{0}, \quad L_{O}=W_{o} \Delta .
$$

The perturbation $L_{O}$ is measured in terms of a bound on $\bar{\sigma}(L)$,

$$
\begin{gathered}
\bar{\sigma}(L) \leq W_{o}(\omega) \quad \forall \omega \\
W_{o}(\omega)=\max _{G \in G_{\Pi}} \bar{\sigma}(L),
\end{gathered}
$$

such that $W_{o}$ covers the entire set of possible plants as shown in Fig. 6. With $W_{u}, W_{t}$ and $W_{p}$ being weighting functions specifying the requirements from section II, the system dynamics are,

$$
\begin{aligned}
{\left[\begin{array}{l}
z \\
v
\end{array}\right] } & =\boldsymbol{P}(s)\left[\begin{array}{l}
w \\
u
\end{array}\right]=\left[\begin{array}{c:c}
P_{11}(s) & P_{12}(s) \\
\hdashline P_{21}(s) & P_{22}(s)
\end{array}\right]\left[\begin{array}{l}
w \\
u
\end{array}\right] \\
u & =K(s) v
\end{aligned}
$$




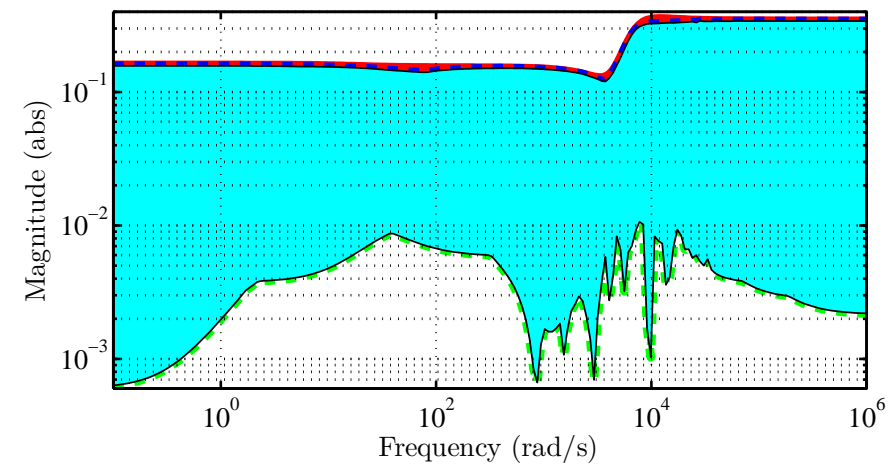

Fig. 6. Relative error $L_{O}$ of $G_{\Pi}$ and uncertainty filter $W_{O}$ with $|\Delta|<1$ for 200 samples of $G_{\Pi}$ representing the relative uncertainty as $G_{\Pi}=(I+$ $\left.W_{o} \Delta\right) G_{0}$. Weighting filter $W_{o}(s)(r-)$, worst case uncertainty (stipple), best case uncertainty (dastdot), relative error area (shaded).

with the matrix $P(s)$

$$
P(s)=\left[\begin{array}{cccc:c}
0 & 0 & 0 & 0 & H_{i_{f 2} v_{i}} W_{o} \\
W_{p} W_{p} G_{i_{f 2} v_{c}} & W_{p} G_{i_{f 2} v_{g}} & -W_{p} W_{p} G_{i_{f 2} v_{i}} \\
0 & 0 & 0 & 0 & W_{u} \\
W_{t} & 0 & 0 & 0 & W_{t} G_{i_{f 2} v_{i}} \\
\hdashline-I & -G_{i_{f 2} v_{c}} & -G_{i_{f 2} v_{g}} & 1 & -G_{i_{f 2} v_{i}}
\end{array}\right] .
$$

The $\mathcal{H}_{\infty}$ controller design opts to minimize the $\mathcal{H}_{\infty}$-norm of the lower fractional transformation of $P$ and $K$,

$$
N=F_{l}(P, K)=P_{11}+P_{12} K\left(I-P_{22} K\right)^{-1} P_{21},
$$

which is the transfer function matrix from exogenous signals $w$ to performance signals $z$. The uncertainty is included as an internal exogenous input, $w_{i}$, and a performance signal $z_{i}$. The external exogenous signals included are the current reference $i_{f 2}^{*}$, the grid disturbance $v_{g}$ and the network disturbance $v_{c}$. The disturbance transfer function matrix $G_{d w}$ maps the exogenous signals to the output current $i_{f 2}$. The disturbance dynamics are specified in the $P(s)$ matrix and provides the relation between the exogenous inputs $w$ and the performance signals $z$. The complex uncertainty description $W_{o}$ is lumped using a third order filter that covers the set of plants in $G_{\Pi}$ as shown in Fig. 6. It is possible to include neglected series and parallel resonances and specific frequency dependent components in the uncertainty description by increasing the order of $W_{O}$. Higher order filter results in a higher order controller and a conservative design. The parametric uncertainty is assumed to be sufficient to cover the frequency dependency within the controller bandwidth.

\section{E. Weighting functions}

The weighting functions specify the relative weight on signal frequency characteristics and should reflect the design criteria set in section II.

$W_{p}$ specifies the tracking performance of the system by bounding the sensitivity below the wanted bandwidth, $\omega_{b i}$, of the system and decrease at high frequencies. The high-pass filter specifies a minimum bandwidth and approximate integral
TABLE II

WEIGHTING FUNCTION PARAMETERS

\begin{tabular}{|c|c|c|c|c|c|}
\hline$W_{p}$ & & $W_{t}$ & & $W_{u}$ & \\
\hline \hline$\tau_{i}$ & $5 e^{-3}$ & $A_{s}$ & 1.65 & $g_{u}$ & $1 / 9$ \\
$A_{p}$ & 2 & $A_{t}$ & 1 & & \\
\hline$g_{p 1}$ & 1.60 & $g_{t 1}$ & 7.12 & & \\
$g_{p 2}$ & 1.44 & $g_{t 2}$ & 7.64 & & \\
$g_{p 3}$ & 0.72 & $g_{t 3}$ & 7.93 & & \\
$g_{p 4}$ & 0.01 & $g_{t 4}$ & 7.51 & & \\
\hline$\omega_{p l}$ & $20 \mathrm{~Hz}$ & $\omega_{t l}$ & $400 \mathrm{~Hz}$ & $\omega_{u h}$ & $3900 \mathrm{~Hz}$ \\
$\omega_{p h}$ & $140 \mathrm{~Hz}$ & $\omega_{t h}$ & $1000 \mathrm{~Hz}$ & $\omega_{u l}$ & $470 \mathrm{~Hz}$ \\
\hline
\end{tabular}

action. The performance weight is found as,

$W_{p}(s)=\frac{s / A_{p}+\omega_{p h}}{s+\omega_{p l} \tau_{i}} \prod_{k=1}^{n}\left(1 /\left(\frac{s^{2}+2 k g_{p} \omega_{b n} \omega_{0} s+\left(\omega_{0} k\right)^{2}}{s^{2}+2 k \omega_{b n} \omega_{0} s+\left(\omega_{0} k\right)^{2}}\right)\right)$,

where $\omega_{b n}$ is the bandwidth of the non-ideal notch filter, $g_{k}$ is the gain of the k'th notch filter and $\tau_{i}$ provides approximate integral action. The performance will be dictated by $W_{p}$ for $\omega<\omega_{b i}$ and by $W_{t}$ for $\omega>\omega_{b i}$ ensuring fulfillment of the second and third requirement. The notch filters are inversely included in the selection of $W_{p}$ to satisfy (33).

The control signal weight, $W_{u}$, is designed to allow for sufficient control effort while realizing the fourth requirement. $W_{u}$ is implemented as a second order weight to increase roll off,

$$
W_{u}(s)=\frac{\left(s / g_{u}^{1 / 2}+\omega_{h}\right)^{2}}{\left(s+\omega_{l}\right)^{2}},
$$

where $g_{u}$ is a tuning parameter to select the attenuation of the filter.

The weighting function on the complementary sensitivity function $W_{t}$ is designed for low attenuation in a narrow band around the $n$ significant harmonics to fulfill the first requirement. It is the upper bound on $T$, and is additionally shaped for high-frequency roll-off and force $T \rightarrow \epsilon$ for all $\omega \in \omega_{h}$,

$$
W_{t}(s)=\frac{s / A_{t}+\omega_{t h}}{s+\omega_{t l}} \prod_{k=1}^{n}\left(\frac{s^{2}+2 k g_{t} \omega_{b n} \omega_{0} s+\left(\omega_{0} k\right)^{2}}{s^{2}+2 k \omega_{b n} \omega_{0} s+\left(\omega_{0} k\right)^{2}}\right) .
$$

The parameters are listed in TABLE II. Picking $A_{p}>1$ provides room for $S>1$ when $u(s) / r(s)>1$, and is necessary to comply with the robust performance bound,

$$
\left\|W_{p}(s) S(s)\right\|_{\infty}+\left\|W_{o}(s) T(s)\right\|_{\infty}<1
$$

and the robust stability bound,

$$
\|T(s)\|_{\infty}<\left\|1 / W_{o}(s)\right\|_{\infty} .
$$

The closed-loop system includes modes associated with the notch filters and thus have an oscillatory impulse response with frequency and damping selected in $W_{t}$. The controller specification designates a $1 \mathrm{~Hz}$ bandwidth of the notch filter which equates a notch filter damping of $\zeta=0.001$. Excitation of notch filter dynamics when tracking the current reference 

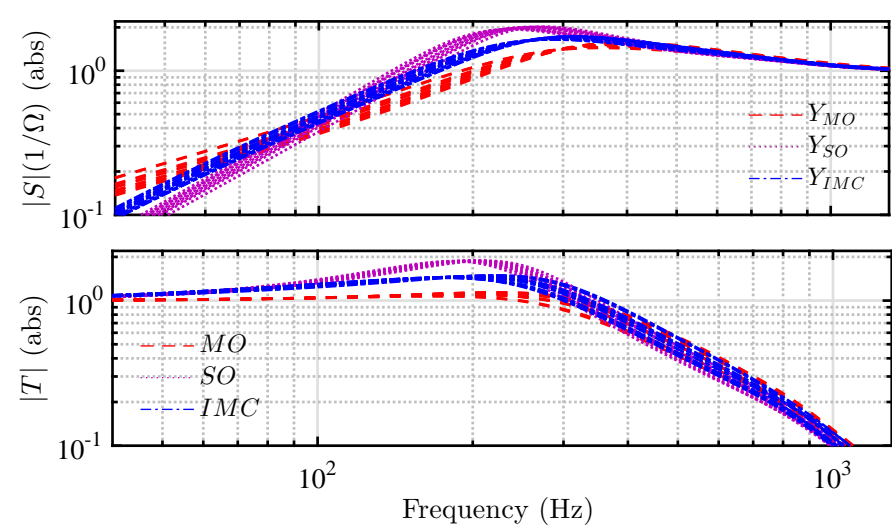

Fig. 7. a) Variation of perturbation bodeplot of closed loop harmonic admittance $(|S|)$ at terminals. MO shows least integral action while IMC and SO are comparable. b) Bode plot of closed-loop $T$. The closed loop performance of the PI loop shaping controllers achieves $|T|>-3 d B$ for $\omega<\omega_{b i}$, but both IMC and SO have resonance peaks $|T|>1$ which leads to overshoot.

is avoided by inclusion of filter $C(s)$ on the reference signal $r(s)$,

$$
r(s)^{*}=C(s) r(s)=\left(\prod_{k=1}^{n}\left(\frac{z_{n}}{p_{n}}\right)\right) r(s),
$$

where $z_{n}$ and $p_{n}$ are the zero and pole pair of the $n$ 'th notch filter in the closed loop, identified by their damping properties. In addition to designing a prefilter, the controller $K$ is reduced from a 77 order design to a 14 order using Hankel optimal model reduction while conserving the notch filter dynamics.

\section{Performance Evaluation}

The closed loop sensitivity function with uncertainty is illustrated in Fig. 7. The Figure shows the integral action and limitations of the PI design as the closed-loop system disturbance rejection cannot be shaped at the power system harmonics. The complementary sensitivity function $T=1-S$ obtains a bandwidth of $0.4 k \mathrm{~Hz}$ as seen in Fig. 7, but cannot guarantee nominal performance for all system perturbations. To asses the performance and quality in regards to the specifications, quantitative metrics $J_{d 1}$ and $J_{d 2}$ are introduced to measure the control effort and sensitivity attenuation at $\omega_{h}$. With $S_{v_{g}}$ being the spectrum of the harmonics,

$$
\begin{aligned}
& J_{d 1}\left(\omega_{h}\right)=\frac{1}{2} \int_{\omega=\omega_{h}-\omega_{d}}^{\omega_{h}+\omega_{d}}\left(\left|H_{i_{v_{i n v}} v_{g}}(\omega)\right|^{2}\right) S_{v_{g}} d \omega \\
& J_{d 2}\left(\omega_{h}\right)=\frac{1}{2} \int_{\omega=\omega_{h}-\omega_{d}}^{\omega_{h}+\omega_{d}}\left(\left.|1-| H_{i_{f 2} v_{g}}(\omega)\right|^{2}\right) S_{v_{g}} d \omega .
\end{aligned}
$$

The normalized worst case gain of the system to output disturbance with respect to both output current and inverter switching is shown in Fig. 8. The duality of the measured metrics and the limitation of the first order compensator with respect to disturbance attenuation and control system limits is clear, as no PI-controller is significantly better at the selected harmonics.

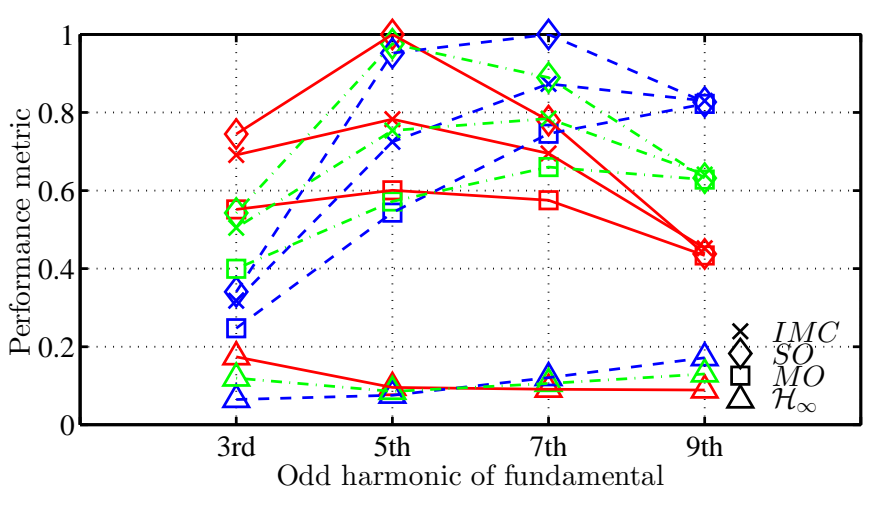

Fig. 8. Normalized $J_{d}\left(\omega_{h}\right) /\left|\left(J_{d}\left(\omega_{h}\right)\right)\right|_{\infty}$, performance metric $J_{d}\left(\omega_{h}\right)$ for IMC, SO, MO and $\mathcal{H}_{\infty}$ controllers. Disturbance to control input $J_{d 1}$ (solid), sensitivity $J_{d 2}$ (stipple) and combined $J_{d}($ dashdot).

\section{SimUlATiON}

The system is evaluated using the performance metric from (36) under worst case uncertainty criteria. The $\mathcal{H}_{\infty}$ optimal design guarantees internal stability of the closed-loop system when $F_{l}(P, K)<1 \forall \omega$. The robust performance and stability is shown in Fig. 10 and the system is stable and performing to specifications for all plants in $G_{\Pi}$. The challenge of tuning the system using notch filters is evident due to the simultaneous increase in amplitude of $W_{p}$ and $W_{t}$. Time domain simulations are performed in an SimPower Systems model of the London Array wind park using an $(\mathrm{N}+1)$ model shown in Fig. 9. Tracking results are shown in Fig. 11a for a doublet step reference change, and the system obtains a rise-time of $1.3 \mathrm{~ms}$ which corresponds to a bandwidth of $0.27 \mathrm{kHz}$ which is lower than the specification. The rise-time is a consequence of the conservatism introduced and having no overshoot, which results in an improved settling time compared to the PIcontrollers. The control effort associated with the reference tracking is shown in Fig. 11b and the $\mathcal{H}_{\infty}$ controller has $25 \%$ less effort compared to the best PI control.

Fig. 12 shows the output response to a disturbance on grid voltage and measurements containing power system harmonics. In Fig. 12a, the controller ensures almost unity sensitivity for the harmonic frequencies and complements the designed filters compared to the phase-lag and amplification of the best PI-controller. Fig. 12b shows an average attenuation of $90 \%$ from noise to output. The fact that noise is rejected when sensitivity is forced towards unity is a fundamental property of control theory and shows how this design methodology can be used to complement the effect of existing filters.

The performance metric from section $\mathrm{V}$ for the $\mathcal{H}_{\infty}$ design in Fig. 8 shows the notch filter design efficiency in obtaining a closed-loop sensitivity $\epsilon \in[0.8 ; 1] . J_{d}$ is close to 0.1 for all $\omega_{h} \pm \omega_{d}$ and improving $J_{d 1}$ and $J_{d 2}$ by minimum $75 \%$.

Robust stability and performance is demonstrated by the multiplicative uncertainty implemented. Uncertainty caused by frequency dependence of components could be represented by using an uncertainty extending throughout a wide range of frequencies. Any additional uncertainty or neglected dynamics could be obtained by using a weighting function of higher 


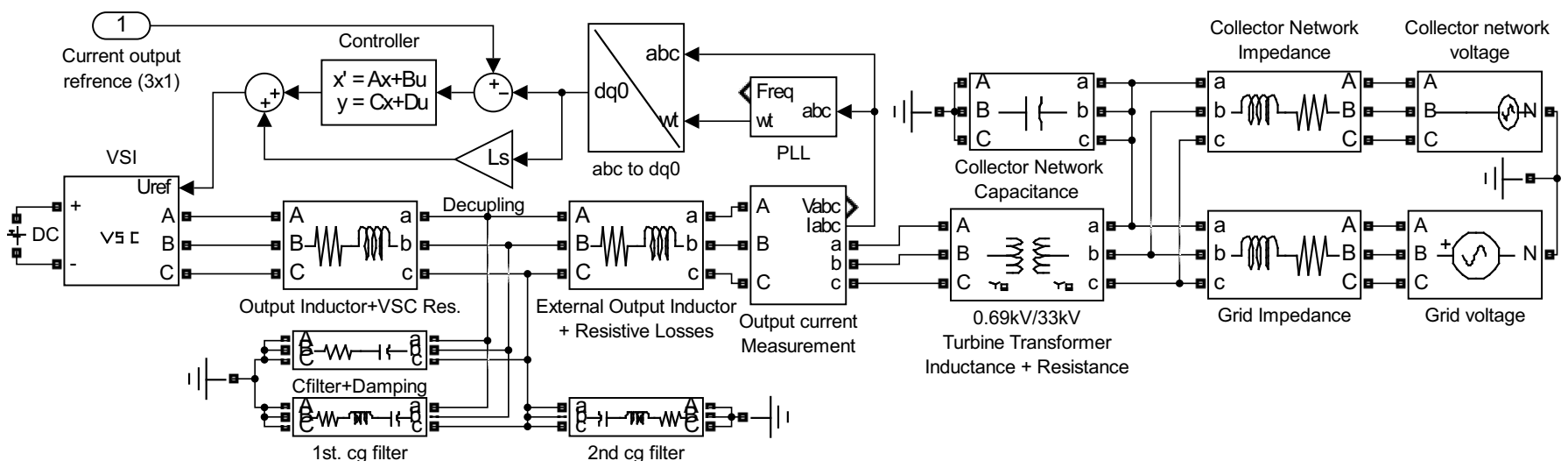

Fig. 9. N+1 model of London Array wind park with generic controller implementation and constant VSI DC-link voltage. The system is balanced and the PLL synchronized with grid voltage vector. Carrier group trap filters are included and tuned to 1st and 2nd harmonic of the switching frequency. Weak PCC/Grid system with an SCR of 20 to emphasize collector network parameter perturbation.

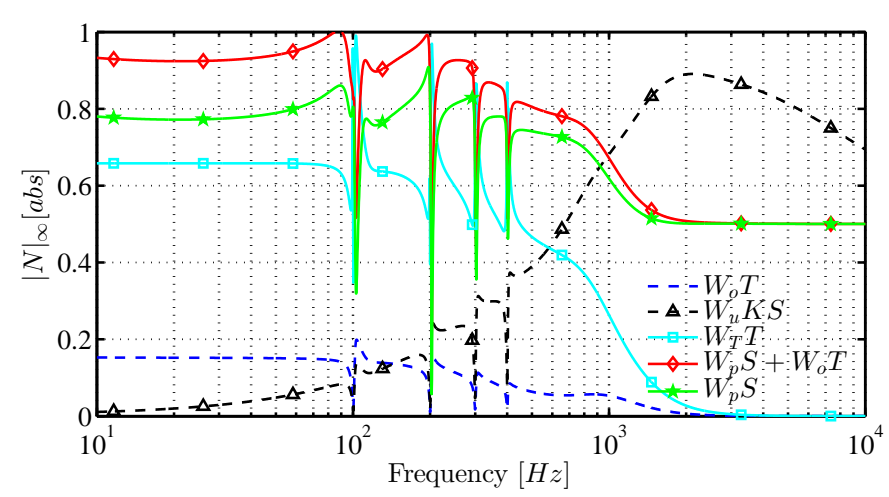

Fig. 10. $\mathcal{H}_{\infty}$ closed loop worst case singular values. $\left|T_{z w}\right|_{\infty}<1$ is obtained and conforms with robust performance (33) and robust stability (34) criteria.
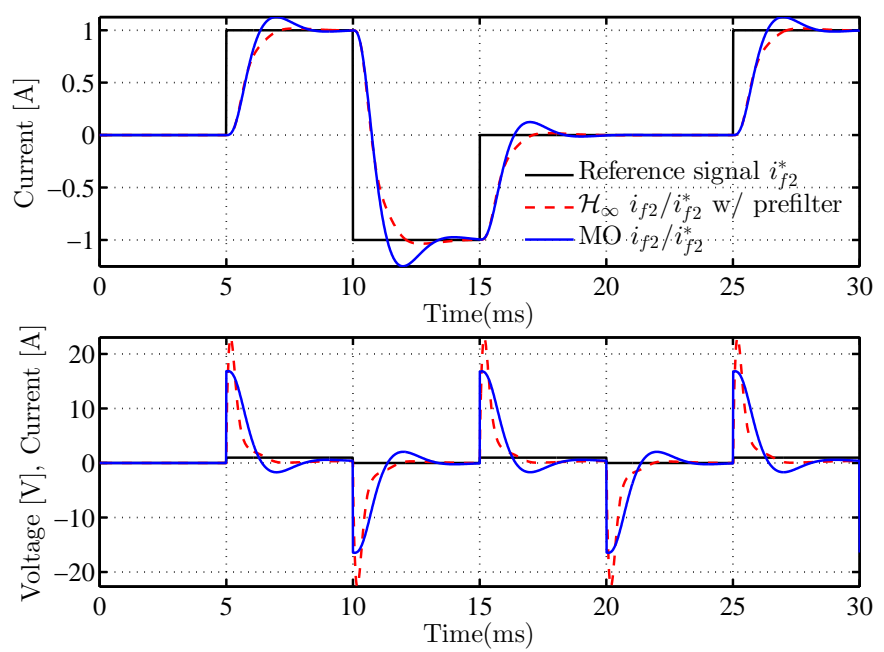

Fig. 11. Reference tracking. a) Output current, $\mathcal{H}_{\infty}$ compared to best PI controller. $\mathcal{H}_{\infty}$ shows faster tracking with no overshoot and within specifications. b) Control effort. $\mathcal{H}_{\infty}$ has a larger initial effort but avoids overshoot and obtains a $25 \%$ reduction compared to PI.
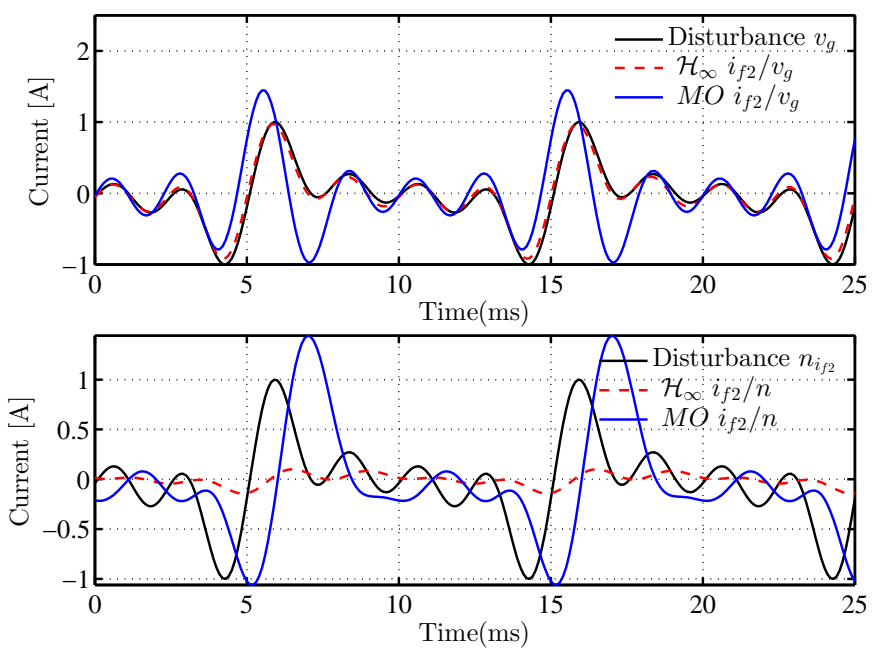

Fig. 12. Disturbance $v_{g}$ and $i_{f 2}$ measurement noise composed of normalized harmonic signal, $\omega=[100 \mathrm{~Hz}, 200 \mathrm{~Hz}, 300 \mathrm{~Hz}, 400 \mathrm{~Hz}]$ a) Disturbance attenuation. Output current, $\mathcal{H}_{\infty}$ compared to best PI controller for harmonic grid disturbance. $\mathcal{H}_{\infty}$ shows compliance within specifications and ensures a sensitivity of unity, while the PI-controller amplifies the disturbance. b) Noise rejection. The controller attenuates power system harmonic noise on the transformer current measurements used in feedback according to the notch filter dynamics.

order [38]. In systems with low frequency series and parallel grid resonances, a more aggressive choice of uncertainty region could be used to ensure robust stability. Such change would affect the controller synthesis towards a conservative design and by an increase of controller order. The extension of the uncertainty region is decided from the uncertainty in wind-park layout. Variations of cable length, placement, specifications and grid strength all contribute to the combined uncertainty. For wind-farms where the relative uncertainty is known, the fixed parameter robust controller instantaneously provides its designed characteristics while additional algorithms in the loop and an adaptation transient is present for adaptive control. If the performance cannot be achieved by 
robust control, adaptive control should be considered [39].

A high order controller in a real-world discrete control structure puts requirements on the computing power needed. Modern WTs are equipped with powerful processors, fiber cables for communication and high frequency measurement equipment. In practice the probable challenges that can arise in implementation are associated with the effects of unmodelled external systems such as the PLL.

\section{CONCLUSION}

Inverter control is a challenging part of designing the output stage of a type- 4 wind turbine. In this paper, traditional loop shaping methods were compared to an $\mathcal{H}_{\infty}$ optimal design with focus on minimizing disturbance rejection for use in inner loop system current control schemes. The $\mathcal{H}_{\infty}$ design using notch filters tuned at the odd harmonic frequencies combined with approximate integral action showed a considerable improvement in performance concerning overshoot, control effort and specific output disturbance rejection. Robust performance and stability was achieved with a uncertainty span equivalent to a collector system with one to multiple connected turbines.

\section{ACKNOWLEDGMENT}

DONG Energy and The Danish Council for Technology and Innovation are gratefully acknowledged for funding of this research.

\section{REFERENCES}

[1] C. Fischer, S. Marithoz, and M. Morari, "A model predictive control approach to reducing low order harmonics in grid inverters with $1 \mathrm{cl}$ filters," IECON Proceedings, pp. 3252-3257, 2013.

[2] H. A. Pereira, S. Y. Liu, M. C. de Lima Ramos, V. F. Mendes, and S. R. Silva, "A comparative analysis of wind turbine technologies in focus on the grid integration," Ind. Appl., (INDUSCON), pp. 1-6, 2010.

[3] H. Pinheiro, V. F. Montagner, and I. J. Gabe, "Design and implementation of a robust current controller for vsi connected to the grid through an lcl filter," IEEE Trans. Power Elec., vol. 24, pp. 1444-1452, 2009.

[4] H. Haitao, Q. Shi, Z. He, J. He, and S. Gao, "Potential harmonic resonance impacts of pv inverter filters on distribution systems," IEEE Trans on Sustainable Energy, 2014.

[5] M. Hasan, K. N. Binti, K. Rauma, A. Luna, J. I. Candela, and P. Rodriguez, "Harmonic compensation analysis in offshore wind power plants using hybrid filters," IEEE Trans. Ind. Appl., vol. 50.3, 2014

[6] L. H. Kocewiak, J. Hjerrild, and C. L. Bak, "Harmonic analysis of offshore wind farms with full converter wind turbines," Int. Conf. Largescale Int. of Wind Power Into Power Sys., vol. 8, 2009.

[7] M. Lindgren and J. Svensson, "Control of a voltage-source converter connected to the grid through and lcl filter application to active filtering," Proc. IEEE PESC, vol. 1, pp. 229-235, 1998.

[8] M. Liserre, F. Blaabjerg, and S. Hansen, "Design and controlf of an lcl-filter based three-phase active re," IEEE Trans. Ind. Appl., vol. no. 5, pp. 12811291,, 2005

[9] R. Beres, X. Wang, F. Blaabjerg, C. L. Bak, and M. Liserre, "Comparative analysis of the selective resonant lcl and lcl plus trap filters," Int. Conf. Opt. of Electrical and Electronic Equip., pp. 740-747, 2014.

[10] J. Lettl, J. Bauer, and L. Linhart, "Comparison of different filter types for grid connected inverter," Proc. PIERS, Marrakesh, 2011.

[11] V. Blasko and V. Kaura, "A novel control to actively damp resonance in input lc filter of a three-phase voltage source converter," IEEE Trans. Ind. Appl., vol. 33, pp. 542-550, 1997.

[12] Y. A.-R. I. Mohamed, M.A.-Rahman, and R. Seethapathy, "Robust linevoltage sensorless control and synchronization of lcl-filtered distributed generation inverters for high power quality grid connection," IEEE Trans. Power Elec., vol. 27, 2012.

[13] S. V. Araujo, A. Engler, and F. L. M. Antunes, "Lcl filter design for gridconnected npc invertersin offshore wind turbines," The 7th International Conference on Power Electronics, pp. 1133-1138, 2007.
[14] A. E. Leon and J. A. Solsona, "Performance improvement of fullconverter wind turbines under distorted conditions," IEEE Trans on Sustainable Energy, vol. 4, pp. 652-660, 2013.

[15] D. Holmes and T. A. Lipo, Pulse Width Modulation for Power Converters: Principles and Practice. IEEE Press, 2003.

[16] E. Lightner and S. Widergren, "An orderly transition to a transformed electricity systems," IEEE Trans. Smart Grid, vol. 1, pp. 3-10, 2010.

[17] M. L. R. Teodorescu, F. Blaabjerg and P. C. Loh, "A new breed of proportional-resonant controllers and filters for grid-connected voltagesource converters," IEEE proc. on Electric Power Applications, vol. 153, pp. 750-762, 2006.

[18] M. Liserre, F. Blaabjerg, and R. Teodorescu, "Multiple harmonics control for three-phase systems with the use of pi-res current controller in a rotating frame," IEEE Trans. Power Elec., vol. 21, 2006.

[19] Z. Zou, W. Zheng, and M. Cheng, "Modeling, analysis, and design of multifunction grid-interfaced inverters with output lcl filter,' IEEE Trans. Power Elec., vol. 29, pp. 3830-3839, 2014.

[20] A. Asbafkan, B. Mirzaeeian, M. Niroomand, and H. A. Zarchi, "Frequency adaptive repetitive control of grid connected inverter for wind turbine applications," 21st Iran. Conf. Electr. Eng., ICEE, 2013.

[21] G. Weiss, Q. C. Zhong, T. C. Green, and J. Liang, "Hinf repetitive control of dc-ac converters in microgrids," IEEE Trans. Power Elec., vol. 19, pp. 219-230, 2004.

[22] S. Jena, B. C. Babu, and L. Sahu, "Experimental study on adaptive hysteresis current controller for inverter-interfaced 1-theta grid connected system," Ind. Appl., (INDICON), pp. 1-6, 2011.

[23] S. Kim, "Sliding mode controller for the single-phase grid-connected photovoltaic system," Applied Energy, vol. 83, pp. 1101-1115, 2006.

[24] J. D. Christian Wessels and F. W. Fuchs, "Active damping of lclfilter resonance based on virtual resistor for pwm rectifiers stability analysis with different filter parameters," Power Electronics Specialists Conference, pp. 3532-3538, 2008.

[25] E. Twinning and D. Holmes, "Grid current regulation of a three-phase voltage source inverter with an lcl input filter," IEEE Trans. Power Elec., vol. 18 , pp. 888-895, 2003

[26] M. Monfared, S. Golestan, and J. M. Guerrero, "Analysis, design, and experimental verification of a synchronous reference frame voltage control for single-phase inverters," IEEE Trans. Ind. Elec., vol. 61, 2014.

[27] R. Barrera-Cardenas and M. Molinas, "Multi-objective optimization of a modular power converter based on medium frequency ac-link for offshore dc wind park," in 10th Deep Sea Offshore Wind R\&D Conference, DeepWind'2013, Trondheim, Norway, 2013.

[28] R. Teodorescu, F. Blaabjerg, U. Borup, and M. Liserre, "A new control structure for grid-connected $\mathrm{lcl}$ pv inverters with zero steady-state error and selective harmonic compensation," Proceedings of Apec 2004, Vol. 1, vol. 1, pp. 580-586, 2004.

[29] E. Muljadi, C. Butterfield, A. Ellis, J. Mechenbier, J. Hocheimer, R. Young, N.Miller, R. Delmerico, R. Zavadil, and J. Smith, "Equivalencing the collector system of a large wind power plant," Power Engineering Society General Meeting, 2006.

[30] J. Brochu, R. Gagnon, and C. Larose, "Generic equivalent collector system parameters for large wind power plant," IEEE Trans. Energy Conv., vol. 26 , Issue: 2, 2011.

[31] B.-G. Cho and S.-K. Sul, "Lcl filter design for grid-connected voltagesource converters in high power systems," IEEE Energy Conv. Cogress and Exp. (ECCE), pp. 1548-1555, 2012.

[32] M. P. Kazmierkowski, R. Krishnan, and F. Blaabjerg, Control in Power Electronics: Selected Problems. Oxford, U.K.: Academic, 2002.

[33] J. P. (ECN), S. de Haan (TUD), J. M. (TUD), E. (ECN), T. van Engelen (ECN), and J. B. (Neg-Micon), "Electrical and control aspects of offshore wind farms ii (erao ii), volume 1: Dynamic models of wind farms," Tech Report, 2004.

[34] J. W. Umland and M. Safiuddin, "Magnitude and symmetric optimum criterion for the design of linear control systems: What is it and how does it compare with the others," IEEE Trans. Ind. Appl., vol. 26, pp. 489-197, 1990

[35] C. Bajracharya, M. Molinas, J. A. Suul, and T. M. Undeland, "Understanding of tuning techniques of converter controllers for vsc-hvdc," Nordic Workshop on Power and Industrial Electronics, 2008.

[36] K.Åström and T. Hägglund, PID Controllers: Theory, Design and Tuning - 2nd edition. Instrument Society of America, 1995.

[37] D. Schrder, Elektrische Antriebe 2, Regelung von Antriebssystemen, 2nd ed. Springer-Verlag, 2001.

[38] S. Skogestad and I. Posletwaite, Multivariable Feedback Control: Analysis and Design, Second Edition. John Wiley \& Sons, Ltd., 2009.

[39] I. Landau, R. Lozano, M. M'Saad and A. Karimi, Adaptive Control: Algorithms, Analysis and Applications. Springer, 2011 


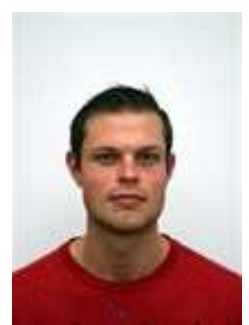

Mikkel P.S. Gryning (S'14) received the B.Sc. and M.Sc. degree in electrical engineering with specialization in automation and robot technology from the Technical University of Denmark (DTU), Lyngby, Denmark in 2009 and 2011 respectively. He was a research assistant with from DTU from Nov. 2011 to Feb. 2012 and has been with DONG Energy SCADA and DTU since Feb. 2012 as an Industrial Ph.D. candidate with focus on power system control.

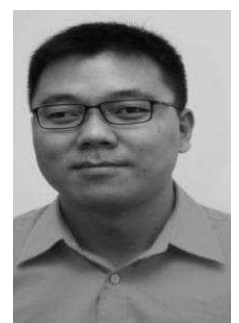

Qiuwei Wu (SM'15) obtained the B. Eng. and M. Eng. from Nanjing University of Science and Technology, Nanjing, P. R. China, in 2000 and 2003 respectively, both in Power System and Its Automation. He obtained the $\mathrm{PhD}$ degree from Nanyang Technological University, Singapore, in 2009, in Power System Engineering. He was a senior R\&D engineer with VESTAS Technology R\&D Singapore Pte Ltd from Mar. 2008 to Oct. 2009. He was a PostDoc with Centre for Electric Technology (CET), Department of Electrical Engineering, Technical University of Denmark (DTU) from Nov. 2009 to Oct. 2010, an Assistant Professor from Nov. 2010 to Aug. 2013 and has been an Associate Professor since Sept. 2013 with the same centre. He is an Editor of IEEE Transactions on Smart Grid.

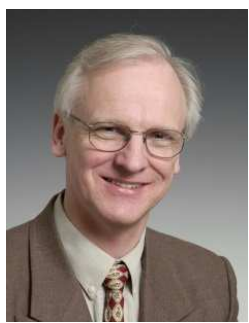

Mogens Blanke (M'74SM'85) received the M.Sc degree in electrical engineering and the Ph.D. degree from the Technical University of Denmark (DTU), Lyngby, Denmark, in 1974 and 1982, respectively. He was a Systems Analyst with the European Space Agency, Paris, France, from 1975 to 1976, at DTU from 1977 to 1984, the Head of the Division at Lyngs Marine from 1985 to 1989, and a Professor with Aalborg University, Aalborg, Denmark, from 1990 to 1999 . He is currently a Professor of automation and control at DTU, and, since 2005, has been an Adjunct Professor with the Center for Ships and Ocean Structures, Norwegian University of Science and Technology, Trondheim, Norway. His research interests include general subjects in automation and control as well as fault diagnosis and fault-tolerant control. Mogens Blanke is Technical Editor for IEEE Transactions of Aerospace and Electronic Systems and Associate Editor for Control Engineering Practice.

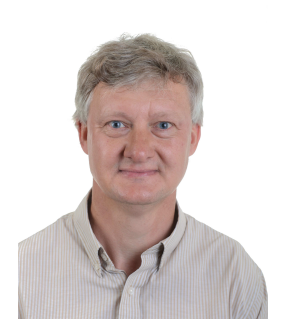

Hans Henrik Niemann Hans Henrik Niemann was born in Denmark in 1961. He received his M.Sc. degree in mechanical engineering in 1986 and $\mathrm{PhD}$ degree in 1988 from Technical University of Denmark. From 1988 to 1994 he had a research position and from 1994 he has been an Associate Professor in control engineering at Technical University of Denmark. His research interests are: Optimal and robust control, fault detection and isolation, active fault diagnosis, fault tolerant control, controller architecture for controller switching and fault tolerant control, system and performance monitoring, controller anti-windup.

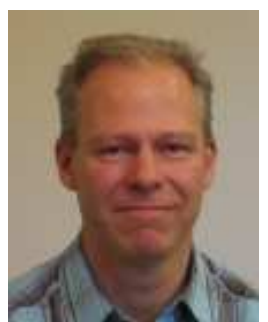

Karsten P.H. Andersen (M'88-91) received the M.Sc.EE degree in electrical engineering and the Ph.D. degree from the Technical University of Denmark (DTU), Lyngby, Denmark, in 1981 and 1985. Assistant professor at DTU 1985-1987 and subsequently Associate Professor at DTU 19871993 within control theory. Engineer at NNEPharmaplan 1993 1994. Starting a consultancy company within advanced process control KH Consult 1995. Chief Engineer NNEPharmaplan 1998 2007. Department manager at DONG Energy within Process Control 2007 2010. Department manager at DONG Energy within SCADA and Wind Farm automation 2010 present. 